false, still must he stand convicted of that other fallacy in argument-viz., of using terms in a totally different sense from that which was given them by the writer whom he is criticising; and then, from the necessarily false deduction so arrived at, of accusing the said writer of a stupid blundes.

I will here add the definition which, in the lectures criticised by Dr. Barclay, I have given of "change of type" in disease; and will leave the reader to judge whether his or my definition of "change of type" is most near to its probable sense. I say probable sense, because, for my own part, I have never yet been able to find the smallest shadow of satisfactory proof that any change in the type of disease has ever occurred.

"I know not to whom is due the credit of first suggesting the term of change of type in diseases, nor when it first appeared in medical literature; nor do I know what was the precise idea attached to it by its inventor; but by the term is meant, as I understand it, not any imaginative alteration in the essential nature of diseases themselves, but some cliange in the condition of the body which is the subject of diseases. Inflammations, I suppose it would be argued, are the same now, in so far as their characters, anatomical and dynamical, are concerned, as they ever were since diseases fell on man; but the body in which they manifest themselves is somehow changed. The general diathesis of humanity has undergone some gradual transformation, so that the manifestations of the reactions of diseases upon mankind are different now from what they were in former days. Moreover, this change, some supporters of the theory tell us, is no partial one; the whole civilised human family has come under the novel phasis. Not only here, but at the antipodes, men will no longer bear the bleedings to which they were once beneficially subjected. And I believe that even veterinary surgeons have found, or have thought to find, the same to be true of the constitution of the animals subjected to their care.

"Besides this, it is not to be imagined that now, for the first time in the history of nosology, such peculiar modifications have occurred in man's nature. The course of diseases amongst mankind, authority assures us, has ever, at different epochs, been marked by variableness and shadows of change. To use the words of the authority referred to: "There are waves of time, through which the sthenic and asthenic characters of disease prevail in succession, and we are at present living amid one of its adynamic phases.' 'I share in the belief' (he adds) 'which has grown out of the experience of many thoughtful and observant men, that, in this country at least, the human constitution has for several years been suffering a gradual change; that alnost all inflammatory disorders assume now-a-days a more adynamic type, and require less energetic treatment than in the early part of the present century.'

"It must also be remembered, that this supposed change in constitution is something quite distinct from the changes in man's bodily state which result from any of the well defined influences of occupation or climate to which he may be accidentally subjected. This peculiar change is, in fact, the resultant of an influence-an unknown influence-totally distinct from those ordinary influences, whose good or evil operations on the body we can note and appreciate; and, as I understand it, it has fallen alike upon allupon the ruddy rustic, the corpulent alderman, the thin, sallow, anxious-faced man of business, and the pallid artisan; affecting each of them, and more and less, according to the varying merits of their constitutions."

\section{rotes ON}

\section{THE ADVANCE OF PHYSIC:} BEING TIIP ANNUAL ORATION BRFORE THE HUNTERIAN SOCIETY FOR 1864-5.

By Jonathan Hutchinson, F.R.C.S., Surgeon to the London Hospital; and Assistant-Surgeon to the Royal London Ophthalmic Hospital.

Mr. President and Gentlemen,-The return of our anniversary, with its customary address, offers an opportunity for general and somewhat discursive remarks, such as wonld be out of place at one of our ordinary meetings. I shall, with your permission, though, I fear, in but a very imperfect manner, attempt a few remarks on the great object which our Society has in view-the improvement of medical and surgical science; or, to use the concise terms of Sydenham, the Advance of Physic. In doing this, I shall venture to submit to your consideration certain matters of detail, as well as more general speculations.

Great as have been the triumphs of our profession in the past, and immense as has been the expenditure of human skill, incustry, and enthusiasm, in achieving them, we have still to regret the exceeding imperfection of our art, in comparison with what the interests of humanity demand. 'Those who have looked most elosely into the matter will probably be the first to admit, and indeed not only to admit, but to exult in the belief, that we have as yet only laid the very foundation-stones of that temple which our profession will, in the future, be privileged to uprear, "to the glory of God, and the good of man's estate."

Chief amongst the means to which we may look for great aid in the future progress of our art, is the much increased use of the pen and of the printingpress. A superficial glance at the present state of things might indeed lead us to suppose that already there exists a glut rather than a deficieney of books and journals. But it is not so. Good buoks are the stones with which we build, and they are still our greatest want. A book written with an honest simplicity of purpose, telling in plain language what we have seen and done, is still the greatest boon which any of us can confer on his profession. We must endeavour to compel our minds to regard books as being simply information-it may be opinions, it may be facts-put into type in order to facilitate reference. The voice of an individual can be heard but by few. The reading of manuscript is tedious and laborious; and, however public may be the place of deposit for manuscript essays, they will remain inaccessible to the majority. Even of our own notebooks, when they have become voluminous, we can make but little use. When, however, an opinion or a fact is once put into good type, and placed upon a publisher's shelf, it is fairiy launched upon the world. It is glorious to refiect how the seed thus sown almost in private and in silence may chance to grow up and fructify where least expected, and possibly to an extent which its sower had never calculated. There are few books which have not some germs of truth, and which do not effect some good; and the public may be very safely left, aided by the labours of critics, to choose the best, and allow that which it finds not usable to sink into disuse. Neither their authors nor the profession need be under any alarm as to superfluous books doing any mischief,-a little extra employment given to the trade, and there the thing ends. The mediocre book drops out of notice, and hurts no one. Many a book, however, which never attains what Mr. Churchill would call success, still serves silently a most useful purpose. 269 
We little know, in the hurried rapidity of life, to what hints we are indebted for the trains of thought which become most valuable to us ; and many a time, could we trace such to their source, we might find ourselves debtors to books or papers which, at the time of perusal, we put aside without a single sentiment of gratitude. It is a curious proverb which remarks, that "the slothful man roasteth not that which he took in hunting." As if his energy failed him at the completion of the chase, and when the excitement was over, he was too idle to consummate his achievements. I have often thought that there is great waste in medical matters, owing to this kind of sloth. We have medical investigators who love the chase for its own sake, and are careless about what it yields. Men of the keenest scent, and of the greatest endurance, whilst out in the hunting-field, are often those who show the least care about the game when it is bagged. I need scarcely explain, that the roasting of the kind of venison I speak of is the publication in a book, or in a journal, of the new knowledge which our prowess has secured us. In doing this, we not only increase its use to ourselves by making it more fit for assimilation, but we have the pleasure of being able to invite our friends to the feast.

It was the fashion with some of the foremost in former days to underrate books. Hunter's habit in this direction is well known; and Sydenham's reply to Sir Richard Blackmore, when asked what medical reading he advised-“ Read Don Quixote, sir"-has been thrown at the head of many a medical author. We may rejoice that the majority have preferred to emulate the example of Sydenham and Hunter, and have declined to feel the force of their sarcasms. In the present day, however, books are far more essential than they were a century or two ago. The man who now neglects them can scarcely hope to advance his art. The first business of the investigator is to climb as quickly as he may upon the shoulders of his predecessors, so that he may view his subject from a fair vantage-ground. I admit that, in many instances, to work out a subject for oneself, and without loading the mind with the opinions of others, gives to the work a freshness and interest which it would not otherwise possess, and secures that searoom for the mind which is so essential to originality. This plan, however, must not be pushed too far ; and no single error has led to a greater waste of labour than injudicious attempts in this direction. The great use of books to students in science is, not for perusal, but for reference; and, in order that reference may be easy, it is needful that the books should be close at hand. If we look at the matter from this point of view, it will, I think, be clear to all, that no greater boon could be conferred on our profession than the cheapening of medical books. Let us have them so cheap that every student can easily afford to have a well stocked library. A little systematic effort in this direction would achieve much. There is surely no good reason why medical books and journals should always maintain their present high rates in comparison with those on general subjects. The chief reason why it is so is, that the demand is limited; and this is a matter which the profession has in its own hands. Let it be acknowledged, that "it is a man's duty to have books-that a library is not a luxury, but one of the necessaries of medical life"; and we shall soon have a corresponding effort on the part of authors and publishers to meet the demand.

The able author of Horce Subsecivo has suggested a classification of medical men founded upon Bacon's use of the terms fruit and light. In the one, we are to class the man of genius, skilled in the search after principles and laws; in the other, the master in the diagnosis and treatment of disease. He quotes $\mathrm{Sir}$ Charles Bell and Harvey as examples of the one; Abercrombie and Sydenham of the other. The one pursue their profession as a science to be taught, and, if possible, to be extended; the other, as an art to be applied. "The one is, in old phrase, luciferous the other, frugiferous". Now, whilst admitting that the classification is founded on observation, it is still one in which we ought not to rest. It is most desirable, for the advance of physic, that all should keep in mind their double functions; that those most engaged in the speculative should still court familiarity with practical details; and those whose daily avocations lead them most into contact with medicine as an applied art, should still keep in mind their duty to use their opportunities for its advancement as a science. The day is happily past when any remonstrance was needed against despising the man of science, and extolling the practical man at his expense; but we need still a more full recognition of the absolute dependence of art upon knowledge. In this country, there is little need to insist upon the importance of practical affairs. There is no fear whatever that light, when obtained, will not at once be made full use of. The English mind certainly tends to err in the opposite direction; and we cannot too often recall Bacon's well known passage: "The industry displayed in experiments is but too often directed by an indiscreet zeal, at some prejudged effect; seeking fruit rather than knowledge. This is in opposition to the Divine method, which in the first day created time alone, delaying its material creations until the sun had illumined space." Or. again, "we are well aware that axioms, rightly framed, will draw after them whole sheaves of works; but, for that untimely and childish desire of seeing fruits of new works before the season, we absolutely condemn and reject it as the golden apple which hinders progress."

Very closely connected with the more wide diffusion of our printed literature, comes the subject of medical education generally. In entering on this most important topic, it is needful that we should rid our minds of all preconceptions as to the connexion between medical education in its true sense, and medical corporations for the granting of diplomas. The interests of the public undoubtedly requir' $\theta$ the existence of these corporations, by whom the portals of the profession are guarded against the ignorant and unsafe. It is no charge against these corporations, however, to say that they have done little or nothing for the advance of physic as a science. Such is not their function, or, at any rate, only indirectly. All true work must be perfectly voluntary. There is nothing that the better parts of our nature so much revolt at as all forms and degrees of compulsion. Although the system of examination for diplomas has done much to maintain a fairly level standard of knowledge throughout the profession, and to protect the public and the profession against empirics, yet it has probably retarded rather than otherwise the advance of physiology and of sound scientific medicine. It has done so by degrading science into a means to an end, instead of leaving her to be worshipped for her own sake. It has associated her pure name with memories of laborious cramming and of hated tasks. It has succeeded in linking what might have been unalloyed pleasures with a consciousness of surveillance and compulsion.

I call to witness the noble progress which the sciences of astronomy and geology have made without any external assistance, when $I$ assert that knowledge is her own reward, and the human mind works best when least trammelled. In adopting this line of argument, however, I by no means wish to underrate 
the importance of our corporate bodies, or to fail in thankfulness for the earnest efforts recently made to improve their operation. The examinations have of late years become much more reasonable and less arbitrary-that is, they have become such as better test a man's real attainments, and leave less and less to the power of mere cramming. When this end shall have been more perfectly attained, their evil influence will much diminish. But whilst it is possible for a student to allege with reason an approaching ordeal at one of the colleges as his motive for absenting himself from the wards and shutting himself up with his books, is there not something wrong? In anatomy, already, this has ceased to be the case, and examinations on the subject render familiarity with the dissecting room essential to success. In medicine and surgery, however, the plan of examining merely by question and answer still leaves the student at liberty, if he likes, to neglect familiarity with that which is the most important part of our vocation-nay, in degree encourages him to do so. I admit the difficulties in the way of examinations for diplomas, conducted with the patients before us, but these are what we must come to if our corporations are ever to exert their due influence in promoting the advance of genuine knowledge.

We must, however, look at medical education in a much wider sense than in so far as it conduces to the creditable obtaining of a diploma. A man's education consists in all that furthers his obtaining acquaintanceship with what is already known by others. Here we draw the distinction between education and original work. Under many circumstances the two may go together, but for the most part they are distinct. The great duty of each generation is to transfer its knowledge in the fullest and most complete manner to its successor. Each endeavours to add its fragments of new knowledge, and then to pass onward to its children the augmented sum. Happy is it, if in its zeal for new additions, it do not allow some items of the old to be forgotten or neglected. This is the great business of education. How best shall it be discharged?

Time does not permit us now to go into detail. One or two general remarks may, however, be ventured. All education should be as far as possible natural, and should be directed to eliciting the student's interest in his subjects, rather than compelling his attention to them. Again, I have to protest that Falstaff but illustrated one of the deepest rooted principles of our nature, when he utterly declined to give reasons upon compulsion. I therefore object for the most part to the establishment of curricula, and to the forced attendance upon certain courses of lectures.

Let our examining boards take more efficient modes of ascertaining what a man knows, and they will have no longer any motive for counting the months he has occupied in gaining his knowledge, or for compelling him to produce evidence that he has sat through certain thousands of lectures. Their object is to test his familiarity with medical science, not to gauge his powers of endurance. Let them attend closely to their own most important duty, and leave the candidates for their diplomas to gain the required knowledge when and where they like. To admit this great principle as one which, by degrees, must sooner or later be carried out, would be to solve one of the questions most under discussion of late in respect to medical education. It has been alleged by some, and with apparent plausibility, that the number of lectures now given is excessive; that the courses are both too numerous and too long. Now, instead of any diminution in the amount of oral instruction offered to our students, we might surely with profit increase it if the objection of compulsory attendance were removed. It is most desirable that the fullest opportunities should be offered at our schools for the acquisition of the most recent knowledge in all branches of study, whether directly professional or only collateral, and that the varied advantages of the lectureroom should be most fully at the service of the student. It should be a matter of choice with the latter, however, whether or not he avails himself of them. If attendance on lectures were voluntary, I do not think the lectures would diminish in number, and I feel sure they would greatly improve in quality. The lecturer would be driven to the final resort of making his lectures instructive, or he would get no class. A healthy rivalry between different professors would be established, which would exercise a most beneficial influence on all.

Under the impression that the sum of medical knowledge has become so vast that it is impossible for the mind to master it without injury to itself, two differentremedies have recently been suggested. The first and boldest is, that the surgeon shall, voluntarily and on system, restrict his studies and throw aside many of the subjects which he has hitherto deemed necessary. The second is, that we shall divide the subject of medical art into various special branches, and some of us take one, and some another. These suggestions are both of them so important in reference to the future advance of physic, that we must devote a few words to each. We will take first the question of specialities.

[To be continued.]

\section{C.ASES OF IIERNIA.}

By Shyuel H. S'teer, M.B.Lond., Abergavenny.

Tre following cases of hernia present some features perhaps sufficiently unusual to render them worth publication in the JourNaL.

CaSE I. October 11 th, 1864 , at 10 A.M., I saw William West, a gentleman's butler, aged $2 \mathrm{~s}$, healthy, but of delicate appearance. He was suffering from symptoms of intestinal obstruction, which had come on shortly after dinner the day before. On examination, I found a soft swelling in the right groin, which he told me had existed since childhood; he had then worn trusses, but he had now left them off for some years. The right testicle was absent. The tumour, though not tense, was a little fuller than usual and rather painful. It gave me the impression that its superficial portion might perhaps consist of the testicle wasted and spread out under the skin. The taxis had no effect. I gave a dose of opium and left, intending to return as soon as possible and administer chloroform. This I did at 4 P.M. He was kept insensible for haif an hour, and the taxis fairly tried. I also had the lower extremities raised over the shoulders of an assistant, and used the taxis while he was in that position, but without making any obvious impression on the tumour, which continued soft and non-resistant. On recovering consciousness, however, he said he was much relieved. I remained with him two hours, and then, vomiting not returning, I left him, desiring to be sent for should the symptoms recur.

I was again summoned at 10 P.M., when I requested my cousin and partner, Mr. Elmes Y. Steele, to accompany me. We found no change in the feeling or appearance of the swelling. It was tender, but not excessively so. Symptoms of strangulation had returned; vomiting was frequent. On consultation, an operation without delay was determined upon-1, because from the feeling of the tumour, from its want of tension and resistance, we were of opinion 